\title{
GENOMIC STRUCTURE AND CHROMOSOMAL LOCALIZATION OF PROCESSED PSEUDOGENES FOR HUMAN RBP-J $\mathrm{J}_{\mathrm{k}}$
}

\author{
Mingdi ZHANG, ${ }^{1,2}$ Xiaoren TANG, ${ }^{1}$ Chunlian $\mathrm{JIN}_{\mathrm{IN}}{ }^{2}$ \\ Frederique Logeat, ${ }^{3}$ Israël Alain, ${ }^{3}$ Shinichi Kondo, ${ }^{1}$ \\ Kailai Sun, ${ }^{2}$ and Kazushige YoKoyama ${ }^{1, *}$ \\ ${ }^{1}$ Tsukuba Life Science Center, The Institute of Physical and Chemical Research (RIKEN), \\ 3-1-1 Koyadai, Tsukuba, Ibaraki 305, Japan \\ ${ }^{2}$ China Medical University, Shenyang P. R. China \\ ${ }^{3}$ Unité Biologie Moléculaire de l'Expression Génique, Department Biologie Moléculaire, \\ Institut Pasteur, 25 rue du Dr Roux, 75724 Paris Cédex 15, France
}

\begin{abstract}
Summary The functional gene for human recombination signal sequence-binidng protein (RBP- $\mathrm{J}_{\mathrm{z}}$ ) and corresponding processed psudogenes have been isolated from various species, such as Drosophila, Xenopus, mouse, and human. Here we report the isolation of another two genomic pseudogenes of human $\mathrm{RBP}-\mathrm{J}_{\mathrm{k}}$, named $\mathrm{K} 2$ and $\mathrm{K} 7$, from a cosmid library of Hela cells. The nucleotide sequences of both genes exhibited more than $95 \%$ homology to the functional human gene for RBP-. $\mathrm{J}_{\mathrm{k}}$. Moreover, they did not contain any intron sequences and were interrupted by several stop codons in all frames. In situ hybridization demonstrated that the pseudogenes, K2 and K7, were localized at chromosomes $9 \mathrm{p} 13$ and $9 q 13$, respectively. Their physical maps differed from those of the true functional gene and of the pseudogenes reported previously by Amakawa et al. (1993).
\end{abstract}

Key Words RBP-J $\mathrm{J}_{\mathrm{k}}$, pseudogene, cosmid, in situ hybridization, physcal map

\section{INTRODUCTION}

The variable (V), diversity (D), and joining (J) recombinations of immunoglobulin genes require conserved recombination signal sequences (RS), namely, a heptamer CACTGTG and a T-rich nonamer GGTTTTTGT, which are separated by a spacer sequence of either 12 or 23 nucleotides (Tonegawa, 1983; Honjo and

Received July 18, 1994; Revised version accepted August 15, 1994.

* To whom all correspondence should be addressed. 
Habu, 1985; Korenberg et al., 1986). The enzymes involved in V-(D)-J recombination as recombinases should recognize the conserved signal sequences, catalyzing site-specific cleavage and ligation of cleaved ends. To date, four genes have been suggested to be involved in the V-(D)-J recombination. These are RAG-1 (Mombaerts et al., 1992), RAG-2 (Shinkai et al., 1992), the scid gene (Lieber et al., 1988; Fulop and Philips, 1990) and RBP-J $\mathrm{J}_{\mathrm{k}}$. The RBP-J $\mathrm{J}_{\mathrm{k}}$ gene has been identified in various species, such as Drosophila, mouse, and human (Furukawa et al., 1991, 1992; Matsunami et al., 1989; Kawaichi et al., 1992; Amakawa et al., 1993), as have analogous pseudogenes (Amakawa et al., 1993).

The RBP- $J_{\mathrm{k}}$ gene has been shown to have been highly conserved during evolution from Drosophila to human (Furukawa et al., 1991; Amakawa et al. 1993). The Drosophila RBP-J $\mathrm{J}_{\mathrm{k}}$ protein is $75 \%$ identical to its murine counterpart (Furukawa et al.. 1991). The human and mouse RBP- $J_{\mathrm{k}}$ proteins are $98 \%$ identical (Amakawa et al., 1993). These proteins have molecular masses of $60 \mathrm{kDa}$ and contain a region of 40 amino acids that is homologous to the integrase motif (Hamaguchi et al., 1989; Matsunami et al., 1989). Recent studies demonstrated the specific binding of mouse RBP- $\mathrm{J}_{\mathrm{k}}$ and human RBP-2N to the sequences $5^{\prime}$ CGTGGGAA-3' and 5'-TGGGAAAGAA-3', respectively (Tun et al., 1994; Dou et al., 1994). The function of this protein in recombination remains to be ascertained. However, the Drosophila homolog of RBP-J $\mathrm{J}_{\mathrm{k}}$ was found to be the Suppressor of Hairless (Furukawa et al., 1991, 1992; Schweisguth and Posakony, 1992), which participates in the regulation of neurogenic expression, an observation that suggests that RBP- $J_{k}$ may play a role in the regulation of gene expression. Dou et al. (1994) recently reported that RBP-2N may have a general role in transcriptional repression. Two types of processed pseudogene for human RBP- $\mathrm{J}_{\mathrm{k}}$ have been isolated and an evolutionary mechanism for their generation has been proposed (Amakawa et al., 1993). However we don't know how many genes are present in human chromosomes. Moreover the genomic organization of these genes included pseudogenes are unknown. In order to understand the structural organization of RBP-J $J_{k}$, we have isolated and characterized the genomic clones of RBP$J_{k}$. We report here the genomic structure and the chromosomal location of two newly identified pseudogenes, K2 and K7, from a cosmid library of Hela cells. These pseudogenes are different from the pseudogenes reported by Amakawa et al. (1993).

\section{MATERIALS AND METHODS}

Screening of a human genomic DNA library. A cosmid library was constructed from the genomic DNA of Hela cells, which was partially digested with Sau3A and then ligated to the cosmid vector pWE15 (Toyobo, Tokyo). The screening of the library (a total of $2.5 \times 10^{6}$ cosmid clones was screened) by colony hybridization with a probe of $1.7-\mathrm{kb}$ EcoRI digested DNA fragment of RBP-J $\mathrm{J}_{\mathrm{k}}$ 
(Sambrook et al., 1989; Amakawa et al., 1993; Feinberg and Vogelstein, 1983). Nucleotide sequencing. The cosmid cloned DNAs were sequenced directly (Slightom and Sieu, 1992) by a modified method as described by Tang et al. (1993).

Restriction maps of cosmid clones. The restriction maps of the cosmid-cloned K2 and K7 DNA were generated by a new method. DNAs were completely digested with EcoRI and their restriction fragments were recovered. Each recovered fragment of DNA was subcloned into the EcoRI-digested pBluescript $\mathrm{SK}^{+}$vector (Stratagene, La Jolla, CA). Each subcloned DNA was purified and sequenced from both flanking regions of each DNA insert with M13 universal primers. Oligonucleotide DNAs as reverse primers were digested on the basis of the nucleotide sequence of each subclone from the $3^{\prime}$ to the $5^{\prime}$ direction and were synthesized on a DNA synthesizer (model 380B; Applied Biosystems, Foster City, CA). Then, the cosmid DNA of $\mathrm{K} 2$ or $\mathrm{K} 7$ was directly sequenced using the primers. A search was made for homology between the nucleotide sequences of cosmid clone K2 or K7 generated with reverse primers and those of the respective subclones generated with M13 universal primers to identify linked subclones. If the nucleotide sequence generated by a reverse primer from a given cosmid clone was homologous to the nucleotide sequence generated by a M13 universal primer from one of the subclones, this subclone should be linked to another subclone containing the nucleotide sequence of the reverse primer that was used for directly sequencing of the previous cosmid clone. Likewise, the linked subclones containing different EcoRI DNA fragments of $\mathrm{K} 2$ or $\mathrm{K} 7$ were ordered.

In situ chromosome hybridization. The preparation of biotin labeled probe of cosmid DNAs, in situ chromosome hybridization and G-banding were carried out as described previously (Lichter et al., 1988, 1990; Zabel et al., 1983).

\section{RESULTS AND DISCUSSION}

In the course of screening a Hela cell cosmid library for human RBP- $\mathrm{J}_{\mathrm{k}}$ genes, we obtained two clones, $\mathrm{K} 2$ and $\mathrm{K} 7$, which hybridized specifically with human RBP-J $_{\mathrm{k}}$ cDNA clone PCR-3 (Amakawa et al., 1993). As shown in Fig. 1a, the EcoRI-digested DNA fragments of K2 were different from those of K7. They were also different from those of the functional human RBP- $J_{k}$ gene and the pseudogenes reported by Amakawa et al. (1993). The DNA fragments of K2 and K7 that had been digested with $E c o$ RI were allowed to hybridize with probe c, derived from mouse RBP-J $\mathrm{J}_{\mathbf{k}}$ DNA, as described by Amakawa et al. (1993). The results (see Fig. 1b) showed that the sizes of hybridized DNA fragments of K2 (3.8 and $1.4 \mathrm{~kb})$ and $\mathrm{K} 7(3.8$ and $1.7 \mathrm{~kb})$ were different from those of the human RBP-J $\mathrm{J}_{\mathrm{k}}$ gene $(18.0,3.8,3.5,2.5$, and $2.1 \mathrm{~kb})$ and those of two known pseudogenes (one, 3.5 and $2.7 \mathrm{~kb}$; the other, 3.8 and $2.7 \mathrm{~kb}$; Amakawa et al. (1993). The EcoRI restriction maps of $\mathrm{K} 2$ and $\mathrm{K} 7$ were compared with the physical maps of the human RBP- $\mathrm{J}_{\mathrm{k}}$ gene and the corresponding pseudogenes (Amakawa et al., 1993) and it 


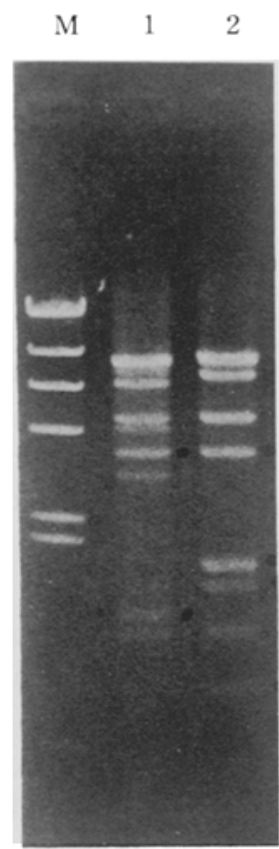

(a)

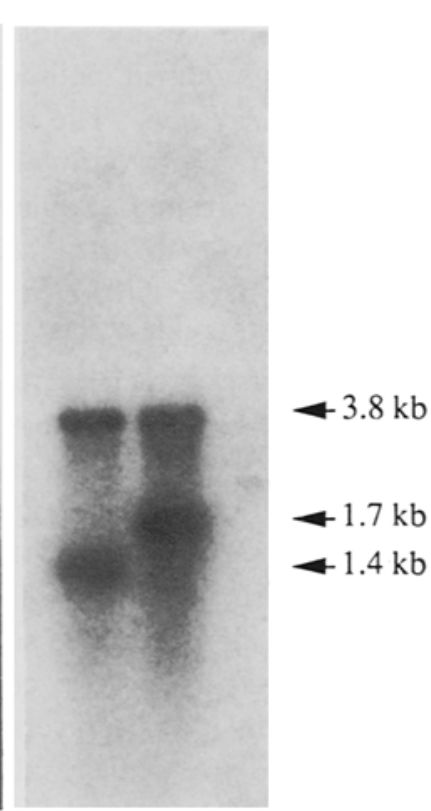

(b)

Fig. 1. (a) Results of agarose gel $(1 \%)$ electrophoresis of EcoRI-digested genomic DNA from K2 (lane 1) and K7 (lane 2). Lanes marked M contain fragments of lambda DNA that had been digested with HindIII. (b) Southern blot analysis of Eco RIdigested genomic DNA from $\mathrm{K} 2$ and $\mathrm{K} 7$ with probe $\mathrm{c}$ from the mouse gene for RBP-J $\mathrm{J}_{\mathrm{k}}$ (Amakawa et al., 1993). The hybridized DNA fragments are indicated by arrowheads $(1.4,3.8 \mathrm{~kb}$, lane $1 ; 1.7,3.8 \mathrm{~kb}$, lane 2$)$.
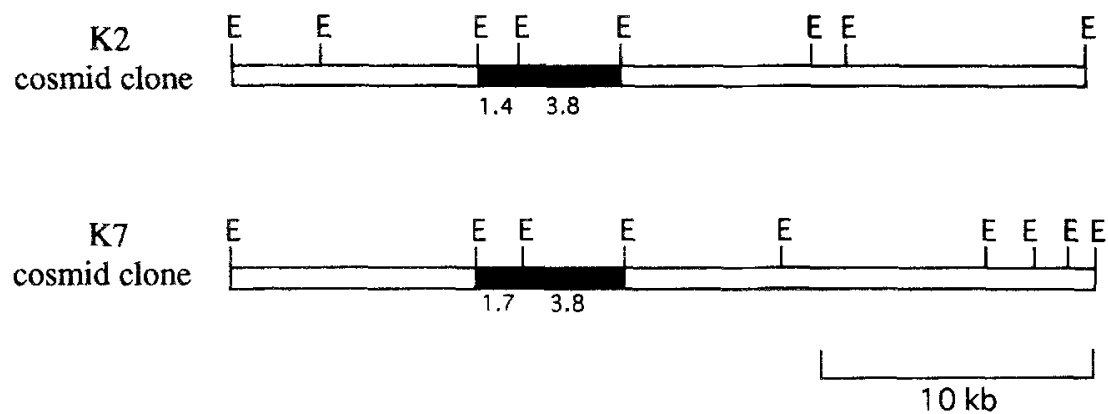

Fig. 2. Genomic structures of pseudogenes $\mathrm{K} 2$ and K7. E indicates a restriction site of EcoRI. Solid boxes indicate the regions specific to probe $c$ from the mouse gene for RBP-I (Amakawa et al., 1993). 
was concluded that they were different clones (see Fig. 2). These data indicated that cosmid clones $\mathrm{K} 2$ and $\mathrm{K} 7$ were new genomic clones of human $\mathrm{RBP}-\mathrm{J}_{\mathrm{k}}$, isolated from a cosmid library of Hela cells.

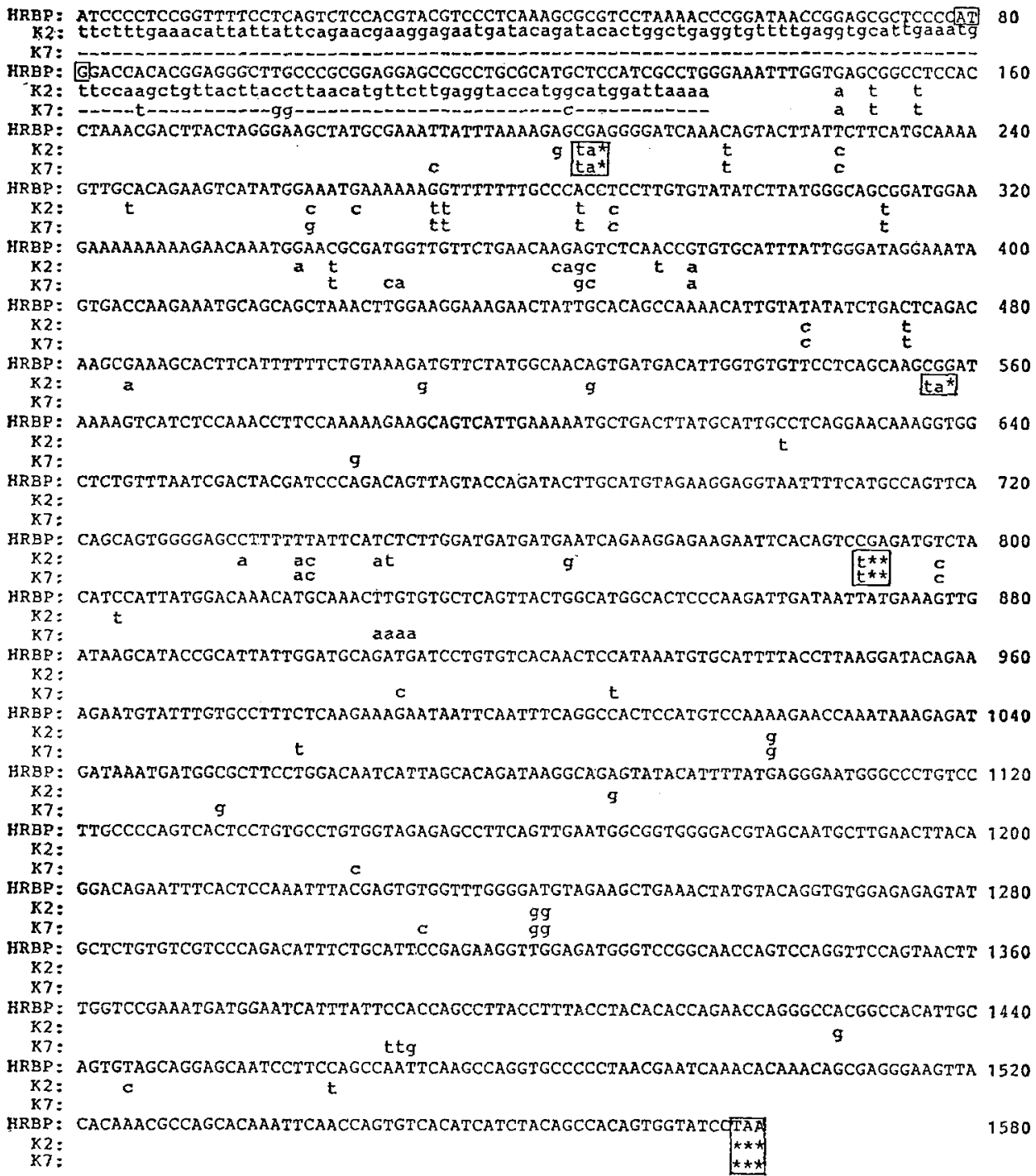

Fig. 3. Comparison of the sequence of the human cDNA for RBP-J $\mathrm{J}_{\mathbf{k}}$ (HRBP; Amakawa et al., 1993) with those of the processed pseudogenes (K2 and K7) isolated in this study. Only non-homologous nucleotides in the sequences of K2 or K7 are shown. Mutated stop codons of $\mathrm{K} 2$ or $\mathrm{K} 7$ are indicated by an open box with asterisks. The translocation start site and the stop codon of HRBP are indicated by an open box. Nucleotide sequences of K2 and K7 have been deposited in GenBank under accession numbers L34543 and L34544, respectively. 

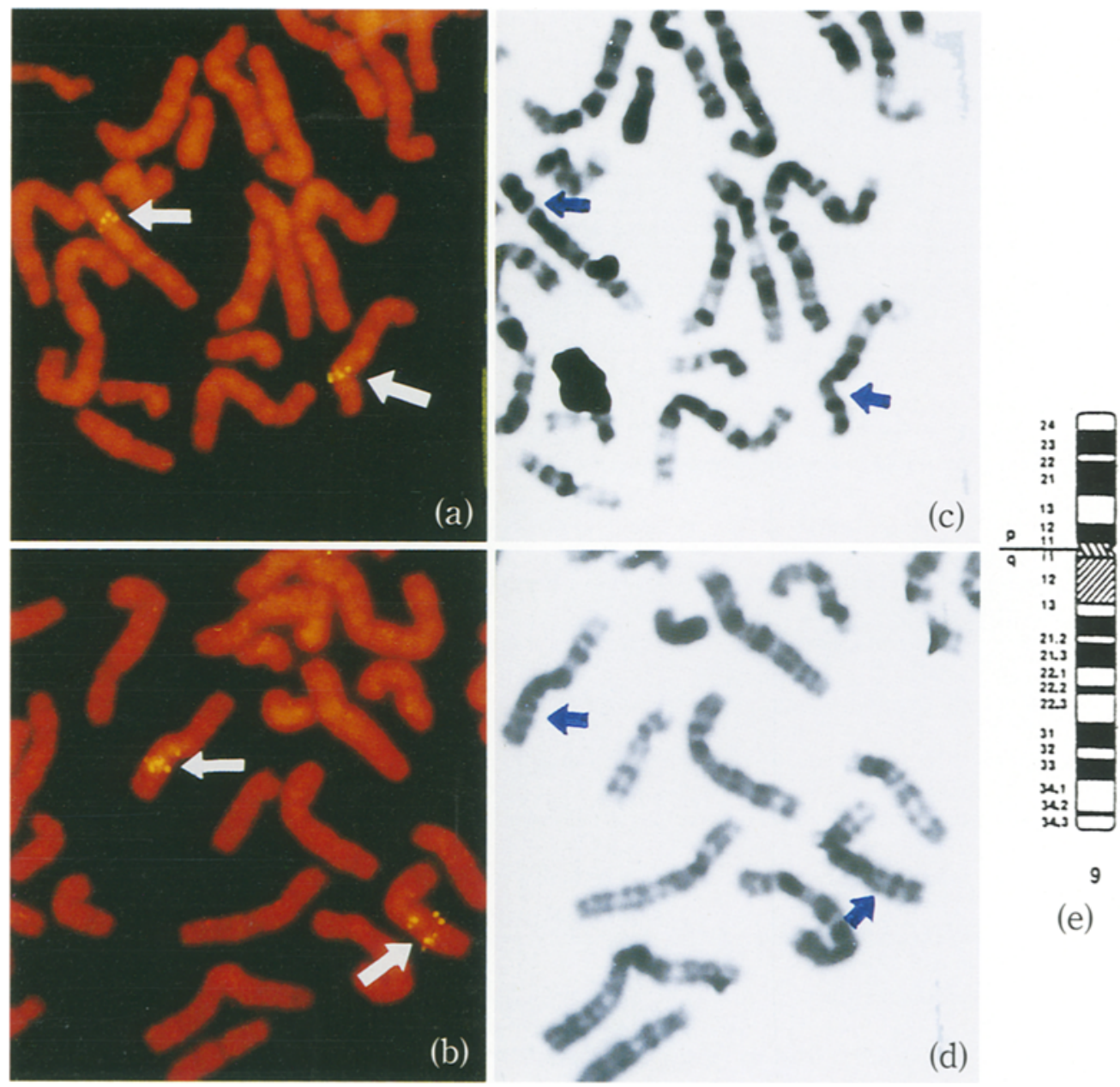

Fig. 4. In situ hybridization on human chromosomes with a biotinylated fragment of $\mathrm{K} 2$ (a) or K7 (b) genomic DNA as probe. ( $\mathrm{a}$ and b) Indirect immunofluorescence detection with propidium iodide counterstaining. (c and d) G-banding of the same chromosome as those shown in (a) and (b). The fluorescent and G-banding spots, indicated by arrows, are located at chromosome $9 \mathrm{p} 13$ and $9 \mathrm{q} 13$ (e).

In an attempt to determine the nucleotide sequences of both the $\mathrm{K} 2$ and the K7 clone, we synthesized several primers that were based on the known nucleotide sequence of the human RBP- $J_{\mathrm{k}}$ gene (Amakawa et al., 1993). First, five oligonucleotide reverse primers were designed, on the basis of the complementary sequence of the human RBP- $J_{k}$ gene from the $3^{\prime}$ to $5^{\prime}$ flanking region, and synthesized, as follows: 1, 5'-GCT GTA GAT GAT GT (positions 1,565-1,552 of the sequence of the human RBP- $\mathrm{J}_{\mathrm{k}}$ gene, accession number: L07872);2, 5'-TTC TTG 
AGA AAG GC (positions 987-974); 3, 5'-AAG GTT TGG AGA TG (positions 580-567); 4, 5'-CTG CCC ATA AGA TA (positions 311-298); and 5, 5'-ACC AGT GTC ACA TC (positions 1,543-1,556). The cosmid DNA of $\mathrm{K} 2$ or $\mathrm{K} 7$ was then sequenced directly using these primers. As shown in Fig. 3, both K2 and K7 exhibited $95 \%$ homology to the human RBP-J $\mathrm{J}_{k}$ gene. A total of over forty mutations, including five (K2) and four (K7) stop codons, were observed and neither sequence contained any introns. We also isolated cDNA clones that corresponded to $\mathrm{K} 2$ and $\mathrm{K} 7$ by using the oligonucleotide probes of coding sequence of HRBP cDNA (data not shown). Thus, we suggest that both cosmid clones $\mathrm{K} 2$ and $\mathrm{K} 7$ represent new processed pseudogenes of human RBP-J $\mathrm{J}_{\mathrm{k}}$.

We next examined the chromosomal location of $\mathrm{K} 2$ and $\mathrm{K} 7$ genes by in situ hybridization (Fig. 4). Intense signals from both $\mathrm{K} 2$ and $\mathrm{K} 7$ were detected at chromosome 9p13 and 9q13 (Figs. 4, a, b, c, d, and e). As reported by Amakawa et al. (1993), the functional human gene for RBP-J $\mathrm{J}_{\mathrm{k}}$ was assigned to chromosome 3 q25 and two pseudogenes 1 and 2 were mapped to 9 p13 and $9 q 13$ respectively. They suggested that multiple copies of pseudogene 1 may exist at $9 \mathrm{p} 13$, and the single copy of pseudogene 2 may exist on 9q13. However we detected multiple copies of the RBP- $J_{k}$ gene in two regions although the signal of $9 \mathrm{p} 13$ was more intense than that of $9 q 13$. The locations of the functional gene and the pseudogenes may differ for the following reasons. (1) The large introns interspersed within the functional gene as reported by Amakawa et al. (1993), of which DNA sequences different from those of the pseudogenes, could contribute to signals at different loci after in situ hybridization. (2) The human functional gene for RBP-J $\mathrm{J}_{\mathrm{k}}$ may have been evolutionarily conserved at chromosome $3 q 25$ during duplication and the pseudogene, without introns, may have been generated by recombination mutation and/or translocation to chromosome $9 \mathrm{p} 13$ and $9 \mathrm{q} 13$. Chromosomal inversion between 9 p13 and 9q13, with subsequent divergence by point mutations, nucleotide insertions and deletions, may have occurred during this duplication. More than four or at least four different genomic pseudogenes of human RBP-J may be present on human chromosomes. These pseudogenes did not contain any intron sequences. We should now try to isolate the remaining pseudogenes for human RBP- $\mathrm{J}_{\mathrm{k}}$, if they exist, and characterize their structures for a comparison with the true gene so that we can attempt to explain the evolutionary mechanism of generation of pseudogenes.

Acknowledgments The authors thank Dr. T. Honjo for the cDNA clone for mouse RBP$\mathrm{J}_{\mathrm{k}}$. This work was supported by Special Coordination Funds of the Science and Technology Agency of the Japanese Government.

\section{REFERENCES}

Amakawa R, Wu J, Ozawa K, Matsunami N, Hamaguchi Y, Matsuda F, Kawaichi M, Honjo $T$ (1993): Human $J_{k}$ recombination signal binding protein gene (IGKJRB): comparison with 
its mou se homologue. Genomics 17: 306-315

Dou S, Zeng X, Patricia C, Hediye E-B, Paul T, Honjo T, Lynne DV (1994): The recombination signal sequence-binding protein RBP-2N functions as a transcriptional repressor. Mol Cell Biol 14: 3310-3319

Feinberg AP, Vogelstein B (1983): A technique for radiolabeling DNA restriction fragments to high specific activity. Anal Biochem 132: 6-13

Fulop GM, Philips RA (1990): The acid mutation in mice causes a general defect in DNA repair. Nature 347: 479-482

Furukawa T, Kawaichi M, Matsunami N, Ryo H, Hishida Y, Honjo T (1991): The Drosophila RBP- $J_{k}$ gene encodes the binding portein for the immunoglobulin $J_{k}$ recombination signal sequence. J Biol Chem 266: 23334-23340

Furukawa T, Maruyama M, Kawaichi M, Honjo T (1992): The Drosophila homolog of the immunoglobulin recombination signal-binding protein regulates peripheral nervous system development. Cell 69: 1191-1197

Hamaguchi Y, Matsunami N, Yamamoto Y, Honjo T (1989): Purification and characterization of a protein that binds recombination signal sequence of the immunoglobulin $\mathrm{J}_{\mathrm{K}}$ segment. Nucleic Acids Res 17: 9015-9026

Honjo T, Habu S (1985): Origin of immune diversity: genetic variation and selection. Annu Rev Biochem 54: 803-830

Kawaichi M, Oka C, Shibayama S, Koromilas AE, Matsunami N, Hamaguchi Y, Honjo T(1992): Genomic organization of mouse $J_{\mathfrak{k}}$ recombination signal-binding protein $\left(\mathrm{RBP}-\mathrm{J}_{\mathrm{k}}\right)$ นวశีe. $\mathrm{J}$ Biol Chem 267: 4016-4022

Korenberg M, Sui G, Hood L, Shastri N (1986): The molecular genetics of the T-cell antigen receptor and $\mathrm{T}$-cell antigen recognition. Annu Rev Immunol 4: 529-591

Lichter P, Cremer T, Tang C-JC, Watkins PC, Manuelidis L, Ward DC (1988): Rapid detection of human chromosome 21 aberrations by in situ hybridization. Proc Natl Acad Sci USA 85: 9664-9668

Lichter P, Chang-Tang CJ, Call K, Hermanson G, Evans GA, Housman D, Ward DC (1990): High-resolution mapping of human chromosome 11 by in situ hybridization with cosmid clones. Science 247: $64-69$

Lieber MR, Hesse JE, Lewis S, Bosma GC, Rosenberg N, Mizuuchi K, Bosma MG, Gellert M (1988): The defect in mouse severe combined immune deficiency: joining of signal sequences but not coding segments in V(D)J recombination. Cell 55: 7-16

Matsunami N, Hamaguchi Y, Yamamoto Y, Kuze K, Kangawa K, Matsuo H, Kawaichi M, Honjo $T$ (1989): A protein binding to the $\mathrm{J}_{\mathrm{k}}$ recombination sequence of immunoglobulin genes contains a sequence related to the integrase motif. Nature 234: 934-937

Mombaerts P, Iacomini J. Johnson RS, Herrup K, Tonegawa S, Papaioannuou VE (1992): RAG1. deficient mice have no mature B and T lymphocytes. Cell 68: 869-877

Sambrook J, Fritsch EF, Maniatis T (1989): Molecular cloning: A laboratory manual, Cold Spring Harbor Laboratory, Cold Spring Harbor, New York

Schweisguth F, Posakony JW (1992): Suppressor of Hairless, the Drosophila homolog of the mouse recombination signal-binding protein gene, controls sensory organ cell fates. Cell 69: 1199. 1212

Shinkai Y, Rathbun G, Lam KP, Oltz EM, Stewart V, Mendelsohn M, Charron J, Datta M, Young F, Stall AM, Alt FW (1992): RAG-2-deficient mice lack mature lymphocytes owing to inability to initiate $\mathrm{V}(\mathrm{D}) \mathrm{J}$ rearrangement. Cell $68: 855-867$

Slightom JL, Sieu LC (1992): Direct sequencing of baculovirus genomic DNA: sequence determination of the engineered respiratory syncytial virus chimeric FG gene. BioTedhniques 13: 94-105

Tang X, Wang Y, Nakata Y, Li H, Fujita A, Gao H, Sarai A, Yokoyama K (1993): A mathema- 
tically designed STS primer without any mismatches for direct sequencing of cosmid DNA clones. Jpn J Human Genet 38: 381-390

Tonegawa S (1983): Somatic generation of antibody diversity. Nature 302: $575-581$

Tun T, Hamaguchi Y, Matsunami N, Furukawa T, Honjo T, Kawaichi M (1944): Recognition sequence of a highly conserved DNA binding protein RBP-J $\mathrm{J}_{\mathrm{k}}$. Nucleic Acids Res 22: 965 971

Zabel BU, Naylor SL, Sakaguchi AY, Bell GI, Shows TB (1983): High resolution of human genes for amylase, proopiomelanocortin, somatostatin, and a DNA fragment (D3S1) by in situ hybridization. Proc Natl Acad Sci USA 80: 6932-6936 